\title{
Developments of policies related to smart cities: a critical review
}

\author{
Sina Keshvardoost \\ Faculty of Science and Engineering \\ University of Wolverhampton \\ Wolverhampton, United Kingdom \\ s.keshvardoost@wlv.ac.uk
}

\author{
Dr Suresh Renukappa \\ Faculty of Science and Engineering \\ University of Wolverhampton \\ Wolverhampton, United Kingdom \\ suresh.renukappa@wlv.ac.uk
}

\author{
Dr Subashini Suresh \\ Faculty of Science and Engineering \\ University of Wolverhampton \\ Wolverhampton, United Kingdom \\ s.subashini@wlv.ac.uk
}

\begin{abstract}
In recent years, the idea of smart sustainable cities has come to the fore. Furthermore, it is quickly gaining momentum, and worldwide attention as a promising response to the challenge of urban sustainability. This pertains especially to ecologically and technologically advanced nations. This paper provides a comprehensive overview of smart (and) sustainable cities in terms of their underlying foundations, assumptions, stateof-the art research development, policies, and future planning practices. As to the design strategy, the paper reviews existing sustainable city models and smart city approaches. Their strengths and weaknesses are examined by focusing on the degree to which cities to the objectives and whether the latter incorporate these goals. To distinguish the related challenges, these models and adopt methodologies are assessed and contrasted against each other in line with the notion of sustainability. The gaps in the exploration inside the field of smart sustainable cities are recognized as in accordance with the research being proposed. Subsequently, a coordinated approach is proposed in view of an applied theoretical perspective to align the existing problems and solutions identified for future practices in the area of smart, sustainable urban planning and smart cities policy development. With regard to knowledge contribution, the paper demonstrates Policy developments related to smart cities in general and particular problems within the policy development, as well as considering the commitment to the application of the policy. Also, diverse country's approach on policies for smart cities and their policy related to Governance It also reveals that numerous research opportunities are available and can be realized within the realm of smart sustainable cities.
\end{abstract}

Keywords - Policy, Developments, Smart cities, Sustainable, Challenges

\section{INTRODUCTION}

The accelerating pace of urbanization in both developing and developed countries, shows new chances to apply emerging technologies to the difficulties of city management. The coordination of urban governance and technology, for the most part referred to as "smart cities" is driven by both global private enterprise and local and national governments seeking to strengthen economic competitiveness and improve quality of life. Regardless of these trends, smart city development (SCD) in developing countries is not as firmly considered as it has been in developed countries [22].

This paper commences by reviewing the factors which differentiate policies for the development of smart cities. Four strategic choices with a spatial reference are recognized: national versus local strategies, strategies for new versus existing cities, hard versus soft infrastructureoriented strategies, and sector-based versus geographicallybased strategies. This includes policies related to mobility, energy, governance, waste, water, education which are discussed including the advantages and disadvantages of each strategic choice, secondly this paper examines strategies adopted globally for smart city. The third part incorporates suggestions for the development of smart cities [22].
This paper also adds to the smart city discourse by clarifying the confusion about strategic choices regarding smart city development and stating the advantages and disadvantages of these strategic choices. A serious examination has been made to draw material together exclusively of the smart city literature. Moreover, the paper provides a starting point for the design of smart city strategies, separating factors by examples of applied strategies in each category, which keeps the smart city conversation ongoing by instigating further research.

\section{A. Smart Cities Concept}

Despite there being agreement that the term smart city, namely, innovation in city management, its services and infrastructures, a specific definition of the term has not yet been stated. There is a wide assortment of meanings of what a Smart City could be.

Two patterns can be clearly recognized in connection with the primary aspects that Smart Cities must take into consideration. From one perspective, there is an arrangement of definitions that put accentuation on just one urban aspect like technology, ecology and so forth. leaving apart the rest of the circumstances involved with a city. This gathering of monotopic depictions causing a misconception that the final goal of a Smart City is to provide a new approach to deal with urban administration in which all perspectives are treated with the interconnection that happens in the real life of the city. Enhancing only one player in an urban ecosystem does not imply that the issues of the entire city are being solved. Then again there are a few creators that stress how the principle contrast of the Smart City idea is the interconnection of all the urban aspects. The tangled issues between urbanization are infrastructural, social and institutional. This intertwining is reflected in the Smart City idea. From the definitions, it can be seen that infrastructures are a central piece of the Smart City and that innovation is the empowering agent that makes it conceivable, however it is the combination, association and combination of all frameworks that which important for a city being genuinely smart [6][15][16].

From these definitions, it can be seen that smart city concept suggests a complete way to deal with city management and development. These definitions demonstrate a balance of the technological, financial and social components associated with a urban ecosystem. The definitions mirror an allencompassing way to deal with the urban issues exploiting the new technologies so the urban model and the connections among the stakeholders can be redefined [3][5][8][12][15].

\section{LITERATURE REVIEW}

This review demonstrations a concise examination of the literature about smart city development policies. Cities require a satisfactory arrangement of framework conditions 
in the field of policy and regulations keeping in mind the end goal is to have the capacity to become smart. The requirement for activity in the field of policy and regulation is highlighted by the following [20]:

\section{A. Regulations that repress smart city roll-out:}

Regulations, extending from local grants for industry, to lawful orders and acts that represent expansive arranging, to struggle with national benchmarks, would all be able to obstruct the execution of smart city systems.

\section{B. Uncertainty:}

Private organisations are reluctant to put resources into new technologies and infrastructure where there is policy uncertainty, and restricted technology integration. Technological uncertainties and differences in technical standards between different nations frequently thwart an expansive scale, that is an European-wide deployment of Smart City ideas.

\section{Ambitions:}

A strategic vision backed up by all stakeholders and supported by long-term policies, directions and systems is the reason for a powerful and productive change process Arrangement, both on a level plane (different policy fields) and vertically (local, regional, national, EU), utilizing a participatory approach which ensures a participatory approach guarantees a holistic view and responsibility regarding the smart city process.

\section{Recommended approach:}

Innovative forms of governance are expected to enable the combination of stakeholders within the procedure. Stages and forums (both formal and ad-hoc) are expected to unite producers and specialists to chip away at the recognizable proof and mapping of conflicts, gaps, hurdles; enhancements to the regulatory framework (improve, abolish, consolidate and simplify); and to have procedures for preparing and training for city partners (sharing of knowledge, best practices)

Activities required on the policy level are: European Innovation Partnership on Smart Cities and Communities Strategic Implementation Plan [11].

1) Encourage cities to build up a Smart City Strategy and implementation plan to provide motivation and implement more prominent acknowledgment across policy domain thinking.

2) Challenge policy and control to enable the application of innovative funding models that join existing public and private funding sources with new kinds of subsidizing, which in the meantime enable urban areas to acquire effect without the funds of other policymakers.

3) Implement " innovation zones " in cities to test and assess the impact of overhauled policies and regulations, and in addition consider extraordinary or decreased type of control in particular fields [20].
TABLE I. SMART CitIES DEVELOPMENT AND POLICY'S PRIORITY AREAS

\begin{tabular}{|l|l|}
\hline Priority Areas & Sustainable Urban Mobility Districts and Built Environment Integrated Infrastructure \\
\hline Citizen Focus & How we include citizens into the process as an integral actor for transformation \\
\hline Policy and Regulation & Creating the enabling environment to accelerate improvement \\
\hline Integrated Planning & How we work across sector and administrative boundaries; and manage temporal goals \\
\hline Knowledge Sharing & How we accelerate the quality sharing of experience to build capacity to innovate and deliver \\
\hline Metrics and Indicators & Enabling cities to demonstrate performance gains in a comparable manner \\
\hline Open Data & How to exploit the growing pools of data; making it accessible - yet respecting policy \\
\hline Standards & $\begin{array}{l}\text { Providing the framework for consistency commonality and repeatability, without stiffing } \\
\text { innovation }\end{array}$ \\
\hline $\begin{array}{l}\text { Businesses Model and } \\
\text { Funding }\end{array}$ & Integrating local solutions in an EU and global market \\
\hline
\end{tabular}

\section{GOVERNMENT POLICIES (EU)}

There are an extensive variety of Government policies and programs which are relevant to developing the UK's capability. They can be assembled in five main areas:

- Empowering and engaging city authorities to build up the vision and leadership to provide solutions to their own problems

- Advancing open information and the limit of associations to enhance access to open data, to share and to utilize it, including the development of open standards; projects to create supporting innovations and to exhibit their efficacy.

- Departmental projects to empower the reception of new approaches and technologies, to change both the service systems and consumer behaviour; taking an interest actively in EU programs.

The 6th key zone of policy is helping UK firms to misuse their capacities in global markets.

\section{A. City Deals to Empower City Authorities}

The Coalition Government is committed to unlocking the maximum capacity of our cities, seeing intense, imaginative spots that can shape their predeterminations and satisfy their potential. In December 2011, the government distributed unlocking growth in cities, propelling a program of city deals. Each arrangement is bespoke, mirroring the distinctive needs of individual places; each arrangement, intends to:

1) Give cities freedom to develop apparatuses they need to drive development.

2) Opens the door for the projects or initiatives that will support nearby economies.

3) Deliver a step-change in governance.

The Cities Policy Unit leads on this work crosswise over Government. To date there are eight cities in England outside London, and new and imaginative methods for doing things that will open development. In February 2013, Government welcomed a further 20 cities and their wider areas to negotiate for the devolution of the specific powers, assets and obligations required to convey their locally determined economic priorities [17].

\section{B. Participating in EU Programmes}

The European Commission has signalled its commitment to build up a European wide capacity to create Smart Cities by setting up a European Innovation Partnership (EIP) on Smart Cities and Communities. The Commission is being supported by a High-Level Group with the power to develop 
imaginative methods to make cities smarter. Which, is upheld by a group of specialists drawn from business. Representatives from the UK are currently shaping this activity. Possible areas of work in this EU context include:

1) Sustainable mobility

2) Sustainable digital infrastructures

3) Low-energy, connected buildings and districts

4) Smarter decision-making in urban planning and in daily life.

\section{SMART Cities IsSUES AND CHALLENGES}

Cities are the main poles of human and economic activity. They hold the possibility to create synergies allowing great development opportunities for their inhabitants. Nonetheless, they also create an extensive variety of issues that can be difficult to handle as they grow in size and complexity. Cities are also the spots where inequalities are stronger and, if they are not legitimately dealt with, their negative impacts can outperform the positive ones.

Urban regions need to deal with their advancement, supporting economic competitiveness, while upgrading social cohesion, environmental sustainability and an increased personal satisfaction of their citizens. With the advancement of new technological innovations primarily ICTs. The concept of the "Smart City" emerges as a way to accomplish more productive and sustainable cities. Since its origination, the Smart City idea has developed from execution of specific projects to the implementation of global strategies to handle more extensive city challenges. In this way, it is important to obtain a comprehensive overview of the accessible possibilities and relate them to the particular city challenges [14].

\section{A. Smart City Challenges}

As cities continue booming tirelessly, their challenges need to be carefully thought through so that population growth, economic development and social advance walk on a similar way.

Although most of global GDP is delivered in urban communities, not all activities happen inside these agglomerations, that implying positive externalities. Cities are additionally the spots where inequalities are stronger, in the event that they are not appropriately dealt with, the negative impacts can outperform the positive ones. The Smart City model can prompt a superior city arranging and administration and along these lines, to the accomplishment of a reasonable model of urban growth. In this paper, challenges have been recognized and put in groups in various measurements with a specific end goal to encourage subsequent stages of the venture. Dissecting the urban condition, research works deal with a different number of fields to frame the city [10].

We have identified in the explored writing that they would all be able to be allotted inside six main City Dimensions:
1) Governance
2) Economy
3) Mobility
4) Environment
5) People
6) Living

They speak to the particular parts of a city whereupon Smart Initiatives attempt to accomplish the normal objectives of a Smart City technique, sustainability, efficiency and high quality of life. Technology itself is not considered an action field, yet an empowering influence that enhances the productivity of the tasks. Inside European cities challenges have been identified [10].

\section{B. City Challenges in European Cities}

These days cities have a wide range of fields where improvements can be made. With the goal that they can turn out to be better places for living. Demographic changes and the financial crisis have revealed the desperation of confronting these city challenges. In any case, it isn't just a matter of the difficulties that smart cities must face today, the future issues of cities must be considered in a coordinated path, as proposed in the record of the European Commission "cities of Tomorrow" [9]. Choices in urban arranging and administration have long haul outcomes. Following this comprehensive approach, every one of these difficulties can be ordered in connection to the Smart City activity fields, as appeared in table II.

The main challenges that cities face in the Smart Governance action field are related with the urgent need for a change of government model. Governance models will face the challenge of making themselves more flexible allowing to possibly of combining their top-down policies with bottomup initiatives and also with informality. Demographic changes and territorial cohesion are the other two main challenges to face [7].

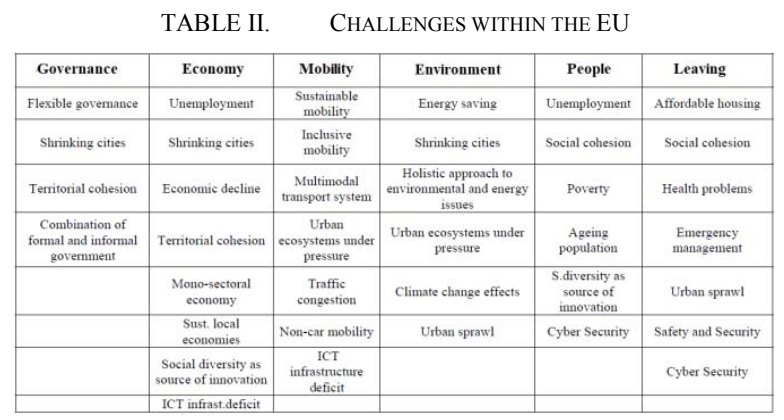

Challenges in the Smart Economy action field are related to the productive structure of the city. After the economic crisis, urban regions have understood the convenience of not focusing their productive model on just one economic sector. Enhancing the creation of a multispectral economy would make cities more resilient to economic downturns, exploiting the unique conditions of each urban agglomeration within a certain region and interconnecting their productive networks which can improve this resistance. Achieving a sustainable, inclusive and efficient mobility system for goods and people is the overall challenge to be dealt with in the Smart Mobility action field. Implementing a multimodal public transport system, fostering alternatives to the car based mobility and making public transport reachable and available to all citizens are the three main axes that will allow reduction of 
congestion and pollution in cities and which will improve connectivity [18]. In the Smart Environment action field, different challenges related with the built and natural environment can be found. On one hand, there is the need for reducing land consumption for the extension of our cities. Enhance a mix of uses, can concentrate the population and ultimately reduce the use of the car. On the other hand, the reduction of energy consumption, pollution and $\mathrm{CO} 2$ emissions is a growing ecological demand for achieving sustainable development. Improving social cohesion and quality of life are the main challenges to face in the Smart People action field. An enriching community life is the final goal, and to achieve then, it is necessary to take initiatives to solve the high levels of unemployment in cities; as well as using the demographic movements and mix of population as an opportunity for innovation, taking into consideration all citizens independently of their age, gender, culture or social condition. The main challenges in this field are related with the supply of housing, health conditions, and crime rate situation. These three aspects, together with the social cohesion of the population are the main issues that set difference for a city to be able to talk about having a good quality of life [14].

\section{TABLE III. CRITICAL REVIEW}

\begin{tabular}{|l|l|l|}
\hline Drivers & Authors & Descriptions \\
\hline Government policy's & $\begin{array}{l}\text { Bhile some authors indicate potential outcomes at a broad level, such as } \\
\text { public value, others establish outcomes based on their potential economic, } \\
\text { environmental and social impact, however the next step to improve the } \\
\text { outcomes is to } \\
\text { provide changes to the government organization; } \\
\text { provide changes in the position of government with regard to other } \\
\text { urban actors; }\end{array}$ \\
\hline apply improvements to the smart city infrastructure;
\end{tabular}

\section{DISCUSSION}

\section{A. Policy recommendations the SMART framework}

The discussions provide insights for developing a model to guide SCD initiatives. The accompanying model envelops five measurements: strategy, monitoring, accountability, rethinking, and transformation. These five can be blended and marked as a " smart " model. This segment quickly plots each of these measurements. Clear strategy is essential for the following three reasons:

1) It establishes an objective that guides the efforts of individuals, government agencies, and businesses.

2) It improves benchmarking by encouraging stakeholders, especially governments and businesses, to survey cases for insights in leveraging strengths and managing weaknesses. 
3) In formulating strategies, governments ideally work with multiple stakeholders, including the private sector, experts, and academics; collaborative buy-in can make implementation more effective and efficient.

Second, checking progress in SCD through key execution markers Key Performance Indicators (KPIs) can enable urban communities to target ceaseless enhancements. KPIs incorporate both process (efficiency) and result measures (quality of life, policy efficacy, equality, and sustainability), with reflections and experiences drawn from every estimation period. KPIs ought to be agreed and composed into SCD ventures at the soonest arranges, as should frameworks for gathering, breaking down, and revealing information. Further, observing endeavours are squandered without an arrangement to cycle experiences once more into the basic leadership process. This requires governments and SCD venture directors to receive a nonstop change mentality, and requires SCD activities to be adaptable in incorporating new discoveries, including to informative advancement and usage. Checking is a key capacity of government and intelligent of both ability and effectiveness, issues recognized as regions of worry among overview respondents.

Finally, as discussed, SCD tends to support operational improvement over governance reform. Fundamental change is important to limit this predisposition. Governments might be inclined to focus on marginal or insignificant items that only signal progress. For instance, a reduction in wait times at road toll booth, signals improvement of traffic bottlenecks, however does not affect the travel demand designs that underlie congestion. Another example, monitoring of tax payments may signal a more operationally efficient fiscal system, however, there is no certification that assessment strategy is accomplishing its social and financial objectives [21].

There technologies are sophisticated enough to overcome poor policy, but cities can use SCD as a mandate to improve overall governance.

These outcomes can be viewed as a first step in clarifying the channels through which investing in policy initiatives based on the SC model can have a positive impact on urban performance, defined in terms of economic growth, quality of life, sustainability and overall well-being. More research is needed to comprehend the overall effect of Smart Cities strategies and how this translates into long-term objectives, along with a more exact definition of what Smart Cities policies really are.

\section{CONCLUSIONS}

The ICT transformation has conveyed connectivity and computing power to developing countries, giving new opportunities to improve productivity and governance. The joining of disparate technologies into operational and institutional frameworks has been broadly embraced through $\mathrm{SCD}$, and governments are presently understanding the value of related investments. It is urgent at this time that administrations grasp SCD in a way that is productive, sustainable, and realistic about its potential. In giving a manual for the improvement of SCD approaches, the smart structure includes five measurements: strategy, monitoring, accountability, rethinking, and transformation. These distinct yet interconnected measurements underline how governments should create SCD's integration with developmental goals, how policies and initiatives should be evaluated, how governments and policymakers in addition these measurements should indicate that how governments can utilize the opportunities exhibited by SCD and to redesign policy and how governments can see the ICT revolution as a broad tool to transform society and achieve unprecedented progress [19].

Smart city projects must be multidimensional and coordinate the distinctive activity fields of the city, connecting with human and social capital. Technological solutions must be comprehended as the apparatus to accomplish the smart city objectives and to handle the difficulties smart cities must face. The primary destinations of Smart City ventures must be to take care of urban issues in a productive approach to enhance sustainability of the city and quality of life of its inhabitants.

Challenges that European cities are facing today can become future challenges in the south if their present ones are not addressed including this vision. Smart city projects must tackle the problems of today's cities while also looking to the potential problems cities will face in the coming decades. Assessment Methodologies are necessary for evaluating the real impact of Smart projects. Classifying existing solutions and projects is a main step for setting the aspects that a methodology must evaluate. These aspects must be related to the previously defined challenges, understanding in which way they provide a solution to the problems of the city. Providing examples in each of the fields, related to these Project actions and challenges, results in a tool to develop solutions to city problems with a multidimensional and comprehensive approach.

\section{REFERENCES}

[1] Ahvenniemi, H., Huovila, A., Pinto-Seppä, I., \& Airaksinen, M (n.d.). What are the differences between sustainable and smart cities? Cities, 60 https://doi.org/10.1016/j.cities.2016.09.009.

[2] Bolívar, M. and Meijer, A. (2016). Smart Governance. Social Science Computer Review, 34(6), pp.673-692.

[3] Batty, M. et al. (2012) Smart Cities of the future. UCL Working Paper Series, Paper 188. ISSN 1467-1298.

[4] Caragliu, Andrea \& Del Bo, Chiara F. (2018) Smart innovative cities: The impact of Smart City policies on urban innovation. Technological Forecasting \& Social Change. [Online].

[5] Caragliu, A.; del Bo, C.; Nijkamp, P. (2009) Smart cities in Europe. 3rd Central European Conference in Regional Science - CERS, 2009.

[6] Chourabi, Hafedh, Taewoo Nam, Shawn Walker, J. Ramon GilGarcia, Sehl Mellouli, Karine Nahon, Theresa A. Pardo, and Hans Jochen Scholl. 2012. "Understanding Smart Cities: An Integrative Framework." Proceedings of the Annual Hawaii International Conference on System Sciences, 2289-97.

[7] Cohen B. Urbanization in developing Countries: Current trends, future projections, and key challenges for sustainability Technology in Society, 28 (1) (2006), pp. 63-80.

[8] Correia, L.M. (2011) Smart Cities Applications and Requirements, White Paper. Net Works European Technology Platform.

[9] EU, (2011) Cities of tomorrow. Challenges, visions, ways forward. European Commission, Directorate General for Regional Policy.

[10] Giffinger, R. et al. (2007) Smart Cities: Ranking of European Medium-Sized Cities. Vienna, Austria: Centre of Regional Science (SRF), Vienna University of Technology.

[11] Glasmeier A, Nebiolo M. Thinking about Smart Cities: The Travels of a Policy Idea that Promises a Great Deal, but So Far Has Delivered Modest Results. Sustainability. 2016;8(11):1122. 
[12] Harrison, C. et al. (2010) Foundations for Smarter Cities. IBM Journal of Research and Development, 54(4).

[13] Lin, Yanliu et al. (n.d.) Toward smart governance and social sustainability for Chinese migrant communities. Journal of Cleaner Production. [Online] 107 (C), 389-399.

[14] Monzon, Andres (n.d.) 'Smart cities concept and challenges: Bases for the assessment of smart city projects', in Smart Cities and Green ICT Systems (SMARTGREENS), 2015 International Conference on. SCITEPRESS. pp. 1-11.

[15] Nam, T. \& Pardo, T.A., 2011. Conceptualizing Smart City with Dimensions of Technology, People, and Institutions. The Proceedings of the 12th Annual International Conference on Digital Government Research.

[16] O'Connell L. Exploring the Social Roots of Smart Growth Policy Adoption by Cities. Social Science Quarterly. 2008;89(5):1356-72.
[17] Public data group https://www.gov.uk/government/groups/publicdata-group [accessed July 2018]

[18] Smart sustainable cities of the future: An extensive interdisciplinary literature review Simon Elias Bibri a, John Krogstieb 2017.

[19] Strzelecka, A., Ulanicki, B., Koop, S., Koetsier, L., van Leeuwen, K. and Elelman, R. (2017). Integrating Water, Waste, Energy, Transport and ICT Aspects into the Smart City Concept. Procedia Engineering, 186, pp.609-616.

[20] Strategic Implementation Plan 2013.

[21] V. Albino, U. Berardi, R.M. DangelicoSmart cities: Definitions, dimensions, performance, and initiatives Journal of Urban Technology, 22 (1) (2015), pp. 3-21.

[22] Vu, K. and Hartley, K. (2017). Promoting smart cities in developing countries: Policy insights from Vietnam. Telecommunications Policy. 